\title{
Enhancing the Antibacterial Efficiency of ZnO Nanopowders Synthesized by Combustion Method Through Ag + Fe Co-doping
}

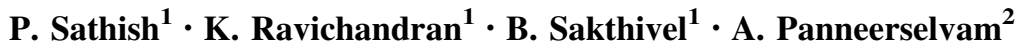

Received: 26 August 2015/Revised: 30 October 2015/Published online: 23 November 2015

(C) The Chinese Society for Metals and Springer-Verlag Berlin Heidelberg 2015

\begin{abstract}
Ag}+\mathrm{Fe})$-doped $\mathrm{ZnO}$ nanopowders have been synthesized using combustion method. Ag doping level was kept as 2 at.\%, and Fe doping level was varied from 3 to 6 at.\%, and the structural, optical, surface morphological, and antibacterial properties have been investigated. The structural studies show that $\mathrm{ZnO} /(\mathrm{Ag}+\mathrm{Fe})$ nanopowders have hexagonal wurtzite structure with a preferential orientation along the (101) plane. The FE-SEM images indicate that there is a gradual decrease in the grain size with the increase in the doping level of Fe, and the TEM images are correlated well with FE-SEM images. The XPS profile clearly confirms the presence of expected elemental composition. Photoluminescence studies reveal the presence of extrinsic defects in the material. Antibacterial activity of Ag-and Fe-doped $\mathrm{ZnO}$ nanopowders against Vibrio parahaemolyticus, Vibrio Cholerae, and Staphylococcus aureus bacteria was also investigated.
\end{abstract}

KEY WORDS: ZnO/Ag/Fe nanopowders; Combustion route; SEM; TEM; Antibacterial activities

\section{Introduction}

$\mathrm{ZnO}$ is $3.37 \mathrm{eV}$ wide band gap semiconductor, which has been an extensively studied material. It is an inexpensive and biocompatible material [1]. It has large free exciton binding energy $(60 \mathrm{meV})$, which makes it a good candidate for semiconductor device applications such as piezo-electric transducers and solar cell windows [2]. Recently, $\mathrm{ZnO}$ nanostructures have attracted intensive attention because of

Available online at http://link.springer.com/journal/40195.

K. Ravichandran

kkr1365@yahoo.com; kkravi1365@gmail.com

1 Post Graduate and Research Department of Physics, AVVM Sri Pushpam College (Autonomous), Poondi, Thanjavur, Tamil Nadu 613 503, India

2 Post Graduate and Research Department of Botany and Microbiology, AVVM Sri Pushpam College (Autonomous), Poondi, Thanjavur, Tamil Nadu 613 503, India their excellent antibacterial properties, which allow a variety of practical applications [3]. In order to enhance the antibacterial efficiency, transition metal doping is an effective way by increasing the carrier concentration [4]. Silver is one of the well-established antibactericidal agents, among various metal dopants which show strong antibacterial efficiency [5]. In our previous study, co- $(\mathrm{Ag}+\mathrm{F})$ doped $\mathrm{ZnO}$ nanopowders have been synthesized using combustion method, and the effect of F doping level on their structural, optical properties along with their antibacterial activities were studied [4]. In the present study, Fe doping level was varied (3 at.\% and 6 at.\%), and Ag doping concentration was kept constant as 2 at. $\%$ in $\mathrm{ZnO}$ nanopowders, and their antibacterial and structural properties were studied.

Fe-doped $\mathrm{ZnO}$ nanopowders are synthesized using several methods which include simple soft chemical [6], coprecipitation [7], microwave [8], and combustion methods [9]. Of these methods, the combustion method is inexpensive, which offers high reaction rate. In the present work, doped $\mathrm{ZnO}$ nanopowders are synthesized using the combustion method. 


\section{Methods and Materials}

\subsection{Synthesis Process}

$\mathrm{ZnO} / \mathrm{Ag} / \mathrm{Fe}$ nanopowders were synthesized using the combustion method. Firstly, $0.2 \mathrm{~mol} / \mathrm{L}$ of zinc nitrate hexahydrate was dissolved in $200 \mathrm{~mL}$ of deionized water. Silver nitrate and ferric nitrate were used as dopant precursors for $\mathrm{Ag}$ (2 at.\%) and $\mathrm{Fe}$ (3 at.\% and 6 at.\%), respectively. Urea was used as a fuel, and suitable amount of ammonia solution was added to keep the $\mathrm{pH}$ value of the starting solution as 9. Polyethylene glycol is added as surfactant which can be used to get the gel formation and to achieve the homogeneity. The prepared mixture was magnetically stirred at room temperature, and the stirring speed was maintained at $650 \mathrm{r} / \mathrm{min}$.

The solution is then shifted to heating mantle, which is maintained at $90{ }^{\circ} \mathrm{C}$ for $2 \mathrm{~h}$. After the ignition process, the setup is allowed to cool for $20 \mathrm{~min}$. The collected ash powder is gray in color, and it is crushed using mortar and pestle until it becomes a fine powder. Now, the powder is calcined at a temperature of $550{ }^{\circ} \mathrm{C}$ for $2 \mathrm{~h}$ using a muffle furnace to get the final product.

\subsection{Characterization of $\mathrm{ZnO} / \mathrm{Ag} / \mathrm{Mn} / \mathrm{F}$ Nanopowders}

The crystalline structure of the synthesized powders was studied using X-ray powder diffraction technique (PANalytical-PW 340/60 X' pert PRO) using $\mathrm{Cu} K_{\alpha}$ radiation $(\lambda=0.15406 \mathrm{~nm})$. Fourier transform infrared (FTIR) spectra were observed using PerkinElmer RX-I FTIR spectrophotometer. Photoluminescence (PL) spectra were recorded using spectro-fluorometer (JobinYvon_FLUROLOG-FL3-11) with xenon lamp (450 W) as the excitation source of wavelength $325 \mathrm{~nm}$. The surface morphology of synthesized $\mathrm{ZnO}$ nanopowders was observed using scanning electron microscope (Carl Zeiss Ultra 55 FE-SEM). Elemental distribution as studied using electron probe microstructure analyzer (EPMA) and the elemental qualitative analysis was carried out using energy-dispersive X-ray analysis (EDAX) attached to EPMA. The microstructure of the synthesized $\mathrm{ZnO}$ nanopowders was analyzed using transmission electron microscope (TEM, Hitachi H-7100). The analysis of the element state was done with X-ray photoelectron spectroscopy (XPS) (ESCALAB 250, Thermo).

\subsection{Evaluation of Antibacterial Activity}

The antibacterial activity of the synthesized $\mathrm{ZnO}$ nanopowders was tested against Vibrio cholerae and vibrio parahaemolyticus (Gram negative) bacteria and one Gram- positive bacteria Staphylococcus aureus using agar well diffusion method. Nutrient agar medium was used for growth of bacteria. This agar medium was sterilized in an autoclave at $121{ }^{\circ} \mathrm{C}$ for $15 \mathrm{~min}$ and then loaded into petri plate and allowed to solidify in a laminar air flow chamber. After solidification, using a sterile cotton swab, fresh bacterial culture was spread over the plate using spread plate technique.

Three wells each of $5 \mathrm{~mm}$ in diameter were made in the agar plates with the help of sterile cork borer. The wells were inoculated with $100 \mu \mathrm{g} / \mathrm{mL}$ of stock solution of the product. All the plates were incubated at $37{ }^{\circ} \mathrm{C}$ for $24 \mathrm{~h}$. After incubation, the plates were observed for the formation of clear inhibition zone around the well. The zone of inhibition was noted by measuring the diameter of the inhibition zone around the well.

\section{Results and Discussion}

\subsection{Structural Studies}

Figure 1 shows X-ray diffraction (XRD) patterns of $\mathrm{Ag}+\mathrm{Fe}$-doped $\mathrm{ZnO}$ samples. The XRD profiles show that all the samples have hexagonal wurtzite structure of $\mathrm{ZnO}$ along with one unmatched diffraction peak observed at $2 \theta=38.065^{\circ}$. This peak is associated with the (111) plane of face-centered cubic structured metal Ag (JCPDS card No. 04-0783), indicating the presence of secondary phase of metal $\mathrm{Ag}$ in the synthesized product. The predominance of (101) peak is not affected by the addition of $\mathrm{Fe}$ and $\mathrm{Ag}$, even at the highest level of Fe doping.

The crystallite size $(D)$ of the doped $\mathrm{ZnO}$ nanopowders is estimated using Scherre's formula [10]:

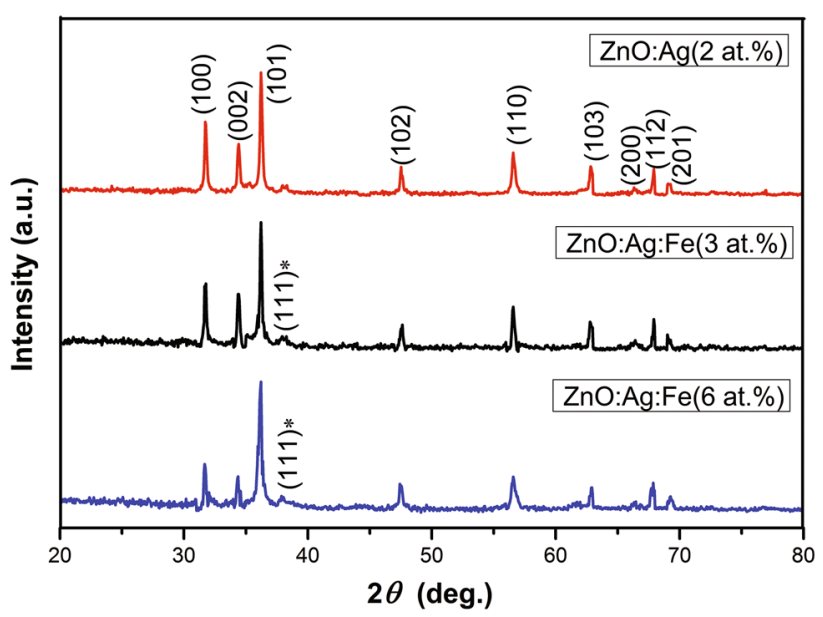

Fig. 1 XRD patterns of $\mathrm{Ag}$ (2 at.\%)- and $\mathrm{Fe}$ (3 at.\% and 6 at.\%)doped $\mathrm{ZnO}$ nanopowders 
$D=\frac{0.9 \lambda}{\beta \cos \theta}$

where $\lambda=0.15406 \mathrm{~nm}$ is the wavelength of $\mathrm{Cu} K_{\alpha}$ radiation, $\theta$ is the Bragg angle, and $\beta$ is the full width at half maximum (FWHM).

The lattice constants ' $a$ ' and ' $c$ ' and volume of the unit cell $(V)$ are calculated using the formulae $[11,12]$ :

$\frac{1}{d^{2}}=\frac{4}{3} \frac{\left(h^{2}+h k+k^{2}\right)}{a^{2}}+\frac{l^{2}}{c^{2}}$.

$V=\frac{\sqrt{3}}{2} a^{2} c$.

The calculated structural parameters are given in Table 1. It is found that the calculated values of the lattice parameter ' $a$ ' and ' $c$ ' and volume of the unit cell $(V)$ are almost consistent with that of standard JCPDS card of $\mathrm{ZnO}$ material. From table, it is seen that the crystallite size of $\mathrm{Ag} / \mathrm{ZnO}$ decreases from $\sim 42$ to $\sim 33 \mathrm{~nm}$ when $\mathrm{Fe}$ doping level increases from 3 to 6 at.\%. The reduction in the grain size of the doped samples may be due to the slight mismatch in the radii of the host and dopant ions [13]. The ionic radius of $\mathrm{Zn}^{2+}$ is $0.74 \mathrm{~nm}$ and that of $\mathrm{Fe}^{3+}$ is only $0.64 \mathrm{~nm}$. This smaller ionic radius of the dopant also causes a marginal decrease in the lattice parameters a and c. This reduced crystallite size plays a crucial role in the antibacterial studies.

\subsection{FTIR Studies}

Figure 2 shows FTIR spectra of Ag- and Fe-doped $\mathrm{ZnO}$ nanopowders. The peak observed at $\sim 485 \mathrm{~cm}^{-1}$ is ascribed to $\mathrm{Zn}-\mathrm{O}$ stretching. When the doping level of $\mathrm{Fe}$ increases, the peak tends to shift from 485 to $443 \mathrm{~cm}^{-1}$. This shift toward lower wave number is due to the incorporation of $\mathrm{Fe}$ ions into the $\mathrm{ZnO}$ lattice sites [14]. The bands approximately at 1395 and $1596 \mathrm{~cm}^{-1}$ are ascribed to asymmetric and symmetric stretching of the carboxyl groups $(\mathrm{C}=\mathrm{O})$, respectively [15]. The peak attributed to $\sim 3420 \mathrm{~cm}^{-1}$ is associated with O-H stretching mode [16].

Table 1 Structural parameters of $\mathrm{ZnO} / \mathrm{Ag}(2$ at. $\%) / \mathrm{Fe}$ (3 at.\%, 6 at.\%) nanopowders

\begin{tabular}{|c|c|c|c|c|}
\hline \multirow[t]{2}{*}{ Sample } & \multicolumn{2}{|c|}{$\begin{array}{l}\text { Lattice constant }{ }^{\mathrm{a}} \\
\left(10^{-1} \mathrm{~nm}\right)\end{array}$} & \multirow[t]{2}{*}{$D(\mathrm{~nm})$} & \multirow[t]{2}{*}{$V\left(10^{-3} \mathrm{~nm}^{3}\right)$} \\
\hline & $' a '$ & 'c & & \\
\hline $\mathrm{ZnO} / \mathrm{Ag}(2)$ & 3.245 & 5.204 & 42 & 47.45 \\
\hline $\mathrm{ZnO} / \mathrm{Ag} / \mathrm{Fe}(3)$ & 3.243 & 5.201 & 37 & 47.41 \\
\hline $\mathrm{ZnO} / \mathrm{Ag} / \mathrm{Fe}(6)$ & 3.241 & 5.199 & 33 & 47.38 \\
\hline
\end{tabular}

$D$ crystallite size, $V$ volume of the unit cell

a Standard values: $a=0.32498 \mathrm{~nm}, c=0.52066 \mathrm{~nm}$ (JCPDS card No. 36-1451)

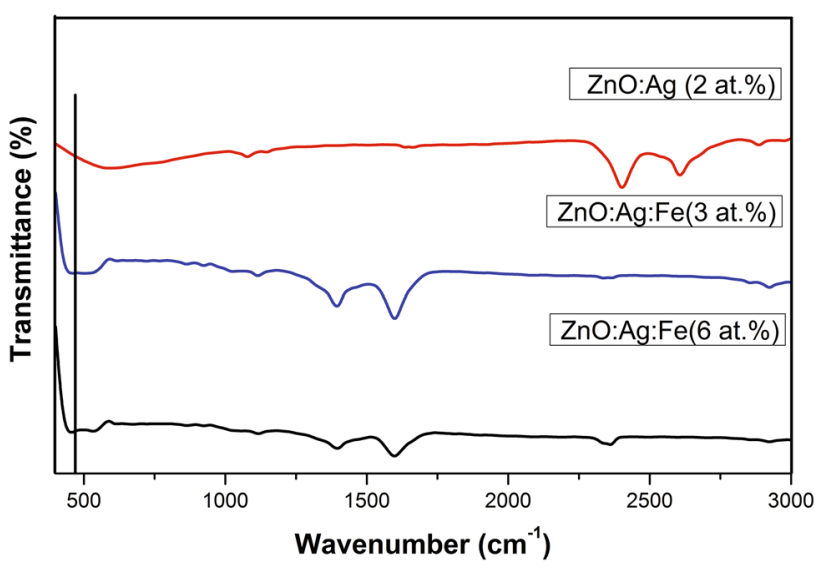

Fig. 2 FTIR spectra of doped $\mathrm{ZnO}$ nanopowders

\subsection{Photoluminescence Studies}

Figure 3 shows PL spectra of doped $\mathrm{ZnO}$ samples showing prominent peaks at 389 and $468 \mathrm{~nm}$. It is well known that the peak at $389 \mathrm{~nm}$ is related to NBE emission which arises due to the band-to-band transition [17]. The increase in the $\mathrm{Fe}$ doping level results in a redshift (increase in wavelength) due to $s p-d$ exchange interactions $[18,19]$.

The peak arises at $468 \mathrm{~nm}$ is owing to the presence of singly ionized oxygen vacancies [20]. The generation of hydroxyl ions is mainly due to this singly ionized oxygen vacancies, which plays a crucial part in the enhancement of the antibacterial efficiency [21].

\subsection{FE-SEM, EDAX, and TEM Studies}

In the case of $\mathrm{ZnO} / \mathrm{Ag}(2$ at.\%) samples, the grain size is found to be around $40 \mathrm{~nm}$. When $\mathrm{Fe}$ is doped with $\mathrm{ZnO} /$ $\operatorname{Ag}(2$ at.\%) nanopowders, the grain size drastically

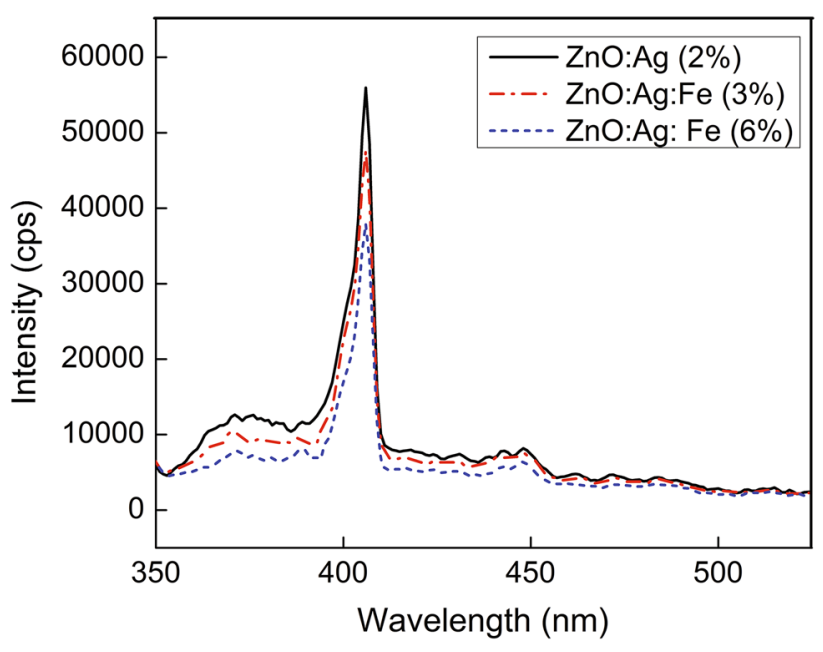

Fig. 3 Room temperature PL spectra of doped $\mathrm{ZnO}$ nanopowders 

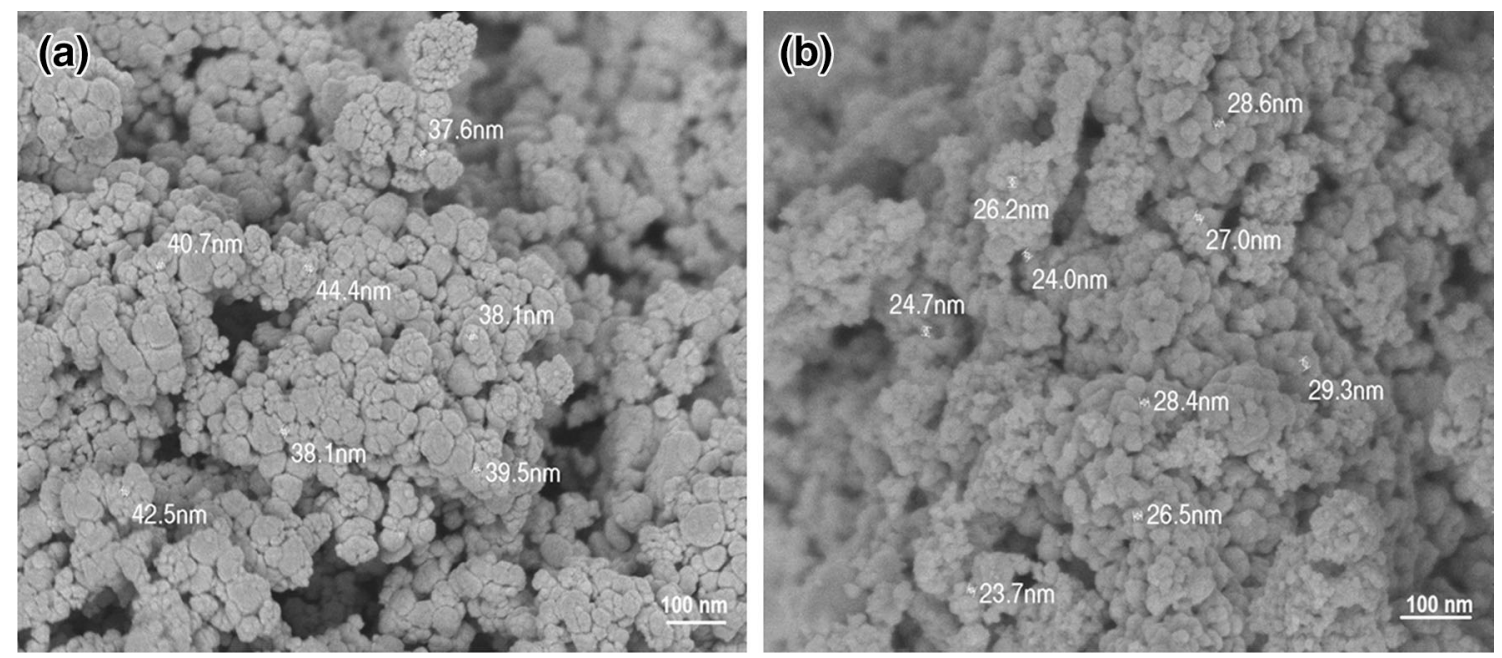

Fig. 4 FESEM images of $\mathrm{Ag} 2$ at.\% (a) and $\mathrm{Ag}+\mathrm{Fe} 6$ at.\% (b)-doped $\mathrm{ZnO}$ nanopowders

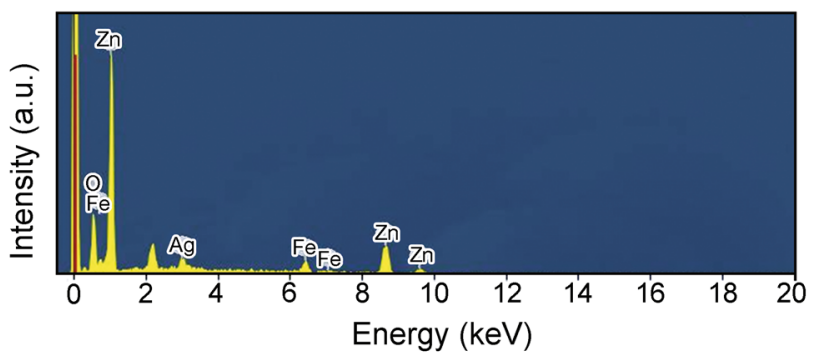

Fig. 5 EDAX spectrum of $\mathrm{Ag}+\mathrm{Fe} 6$ at.\% -doped $\mathrm{ZnO}$ nanopowder

reduces. When the doping level is at 3 at.\%, the grain size is found to be around $26 \mathrm{~nm}$, and the value reduces further to $22 \mathrm{~nm}$, when the doping level is 6 at.\%, which may be due to the formation of $\mathrm{Fe}_{3} \mathrm{O}_{4}$ [22]. This reduction in grain size, as shown in Fig. 4, exhibits a remarkable impact on the antibacterial efficiency of the synthesized samples.
The energy-dispersive X-ray analysis spectrum of $\mathrm{Ag}+\mathrm{Fe}$-doped $\mathrm{ZnO}$ nanopowders is shown in Fig. 5. The analysis shows the presence of the expected elements $\mathrm{Zn}$, $\mathrm{O}, \mathrm{Ag}$, and $\mathrm{Fe}$ in the synthesized sample.

The TEM images of Ag-doped and Ag + Fe-doped $\mathrm{ZnO}$ nanopowders and the size and shape of the particles are well correlated with FE-SEM results as shown in Fig. 6. The size of the nanoparticles decreases with the increase in the Fe doping level.

\subsection{XPS}

Figure 7 shows XPS measurements were investigated to study the existing states of $\mathrm{Fe}$ and $\mathrm{Ag}$ in the $\mathrm{ZnO}$ samples. The two peaks at 1025.5 and $1046.6 \mathrm{eV}$ correspond to binding energies of $\mathrm{Zn} 2 \mathrm{p}_{3 / 2}$ and $\mathrm{Zn} 2 \mathrm{p}_{1 / 2}$, respectively, indicating that $\mathrm{Zn}$ is present in the form of $\mathrm{Zn}^{2+}$ [23]. In
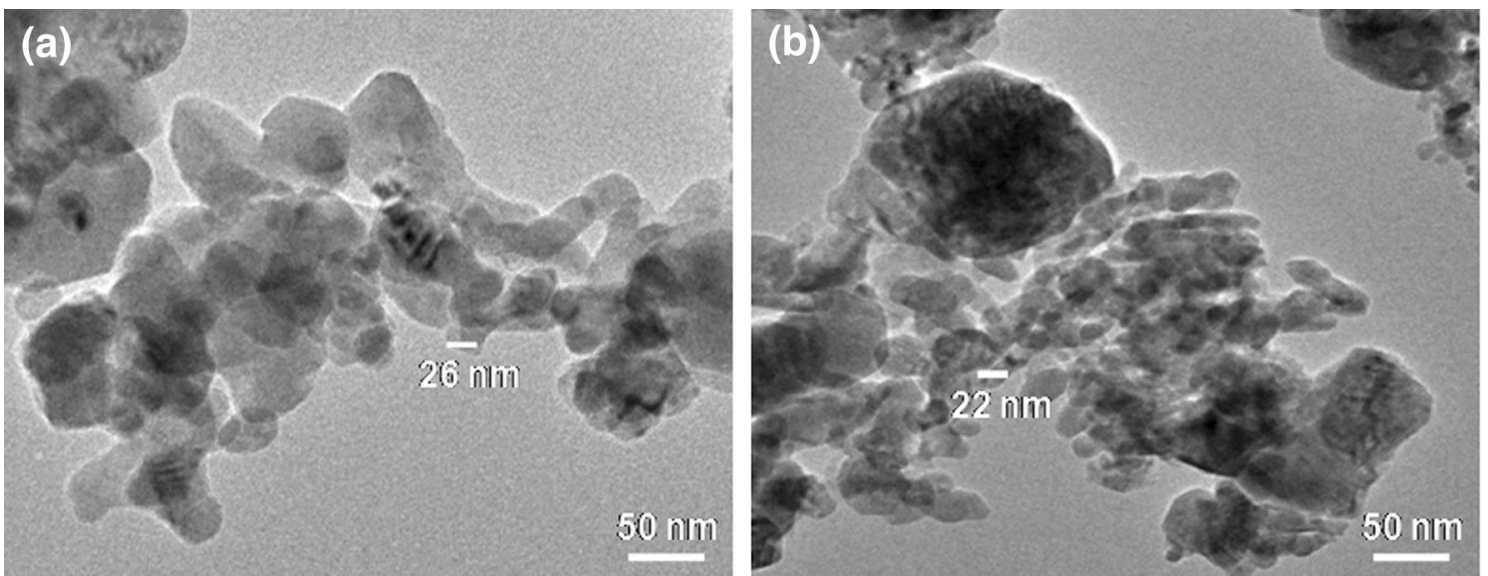

Fig. 6 TEM micrographs of Ag- 2 at.\% (a) and $\mathrm{Ag}+\mathrm{Fe} 6$ at.\% (b)-doped $\mathrm{ZnO}$ nanopowders 


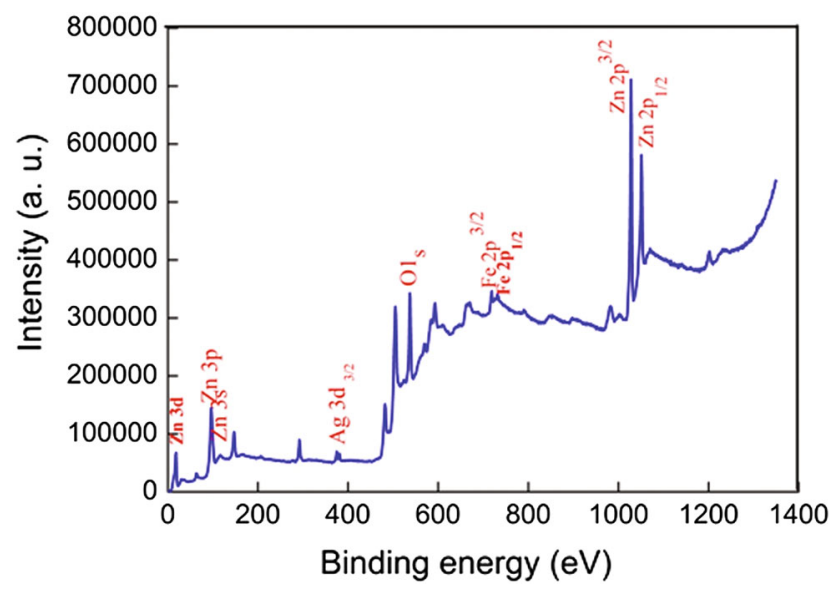

Fig. 7 XPS spectrum of doped $\mathrm{ZnO}$ nanopowders
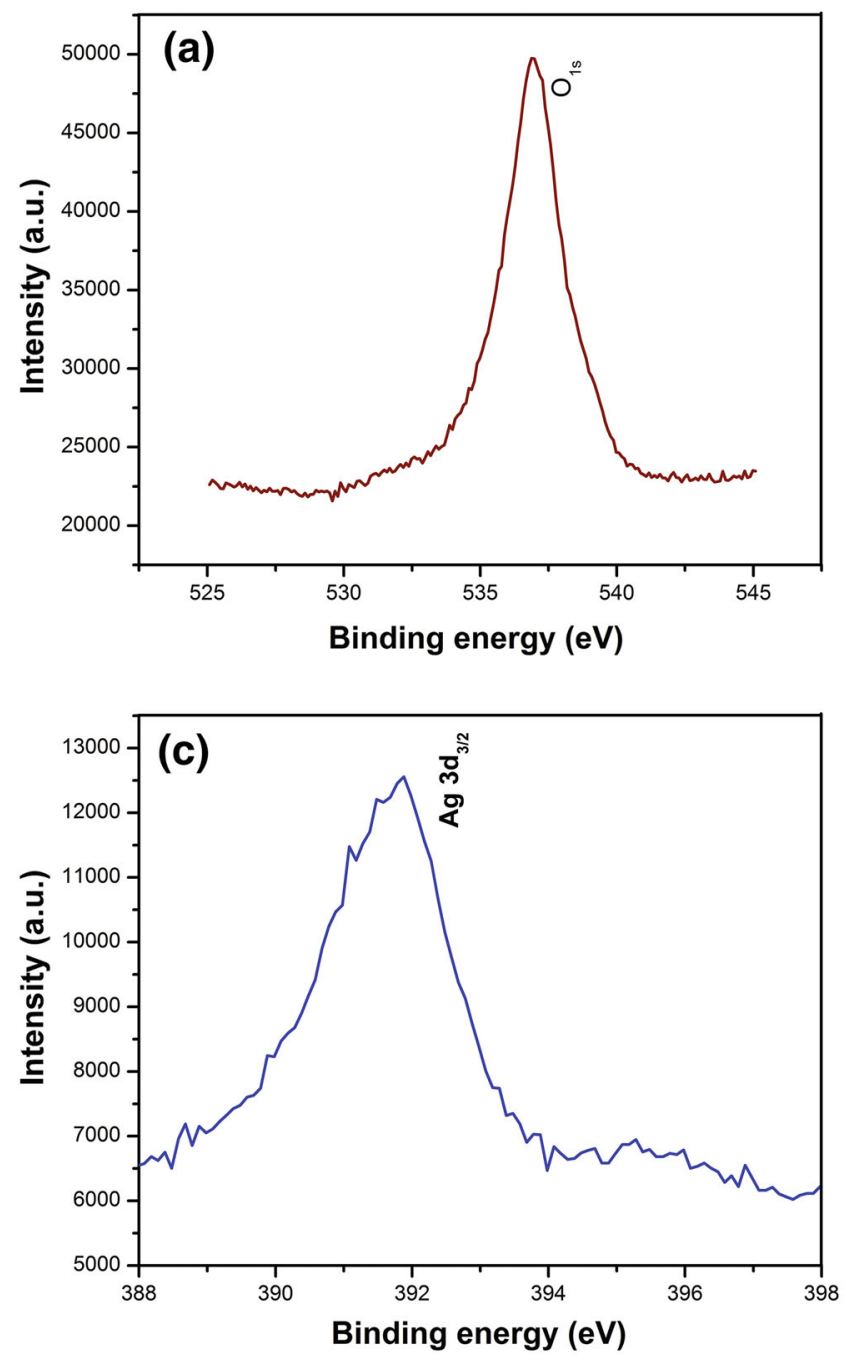

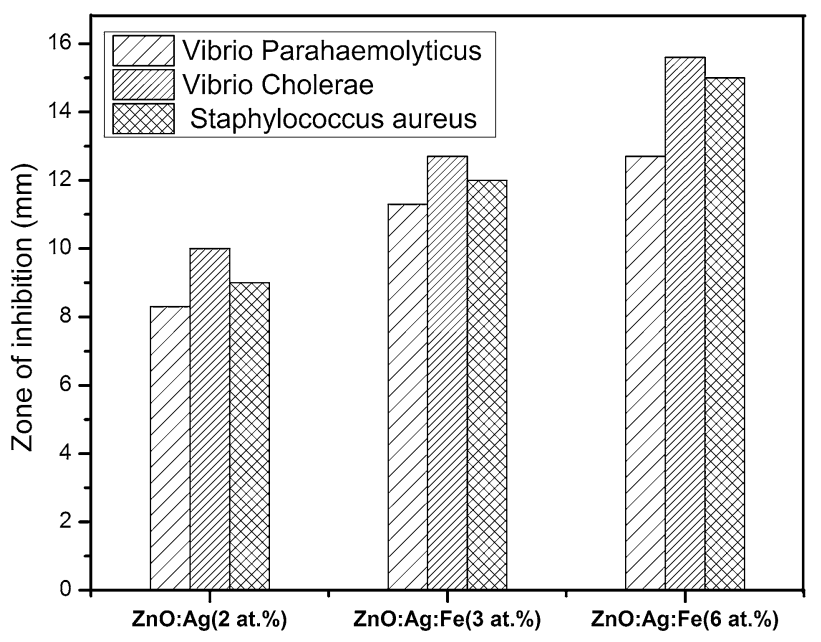

Fig.9 Variation in zone of inhibition as a function of 2 at.\% $\mathrm{Ag}$ and 3 at.\%, 6 at.\% Fe doping
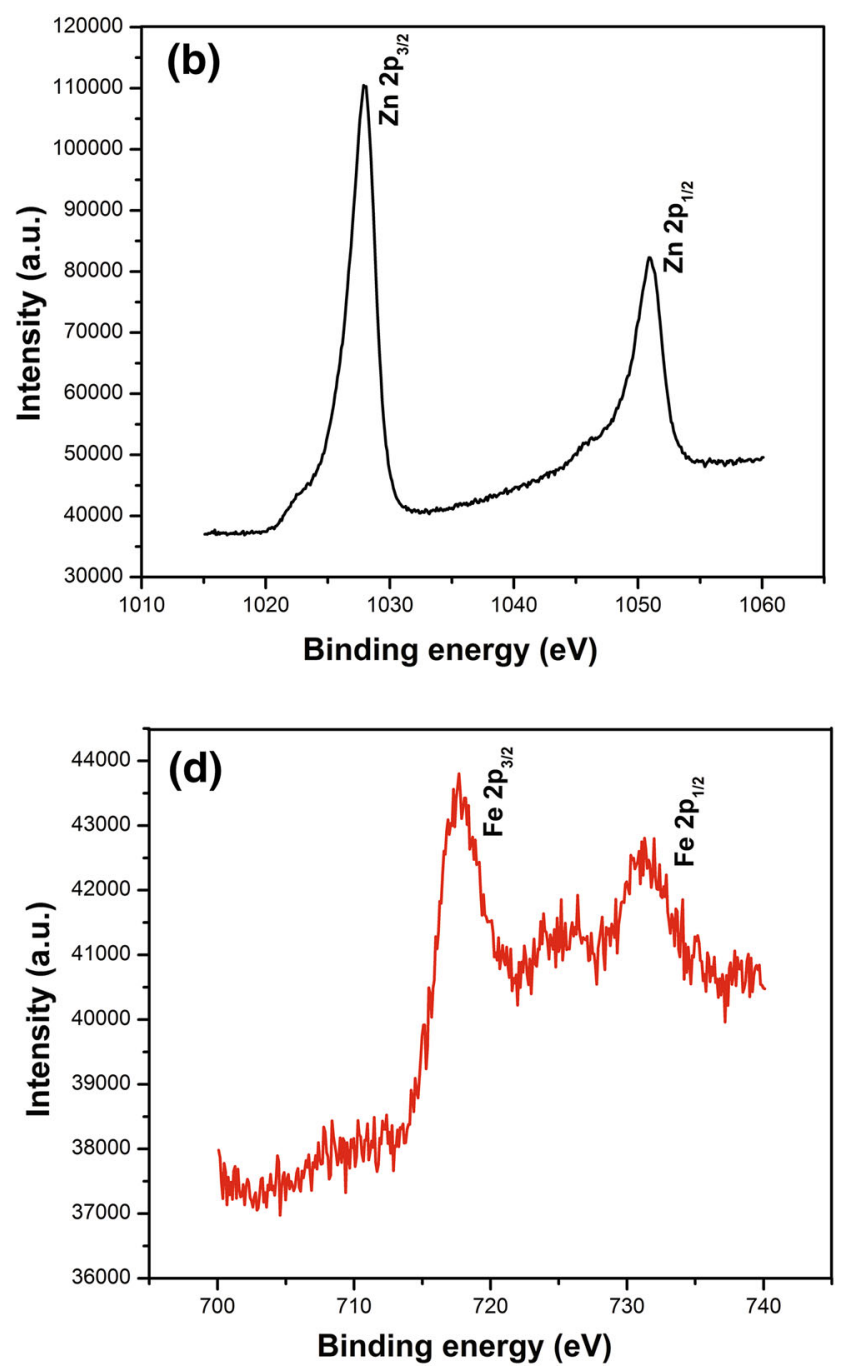

Fig. 8 High-resolution XPS spectra of O (a), Zn (b), $\mathrm{Ag}(\mathbf{c})$ and $\mathrm{Fe}(\mathbf{d})$ 

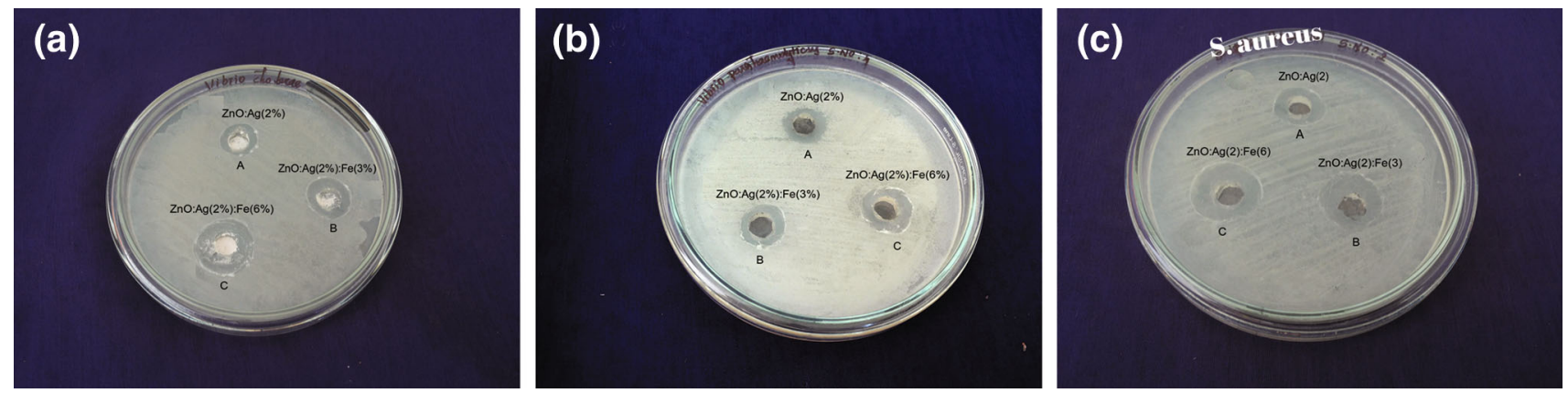

Fig. 10 Zone of inhibition of 2 at.\% $\mathrm{Ag}$ and 3 at.\% and 6 at.\% Fe-doped $\mathrm{ZnO}$ nanopowders against V. Cholerae (a), V. Parahaemolyticus bacteria (b), S. aureus (c)

the XPS spectra of the $\mathrm{O} 1$-s region, the peak at $534.3 \mathrm{eV}$ can be ascribed to $\mathrm{O}^{2-}$ ions that are in oxygen-deficient regions inside the matrix of $\mathrm{ZnO}$. The peaks at 716.1 and $728.7 \mathrm{eV}$ are in accordance with the binding energies of $\mathrm{Fe} 2 \mathrm{p}_{3 / 2}$ and $\mathrm{Fe} 2 \mathrm{p}_{1 / 2}$, respectively. The XPS signals for $\mathrm{Fe}^{2+}$ and $\mathrm{Fe}^{3+}$ ions are in close proximity to $\sim 710 \mathrm{eV}$ for the $\mathrm{BE}$ of $\mathrm{Fe} 2 \mathrm{p}_{3 / 2}$ which specify Gaussian fitting results [24]. Figure $8(a-d)$ shows the high resolution XPS spectra for the elements of $\mathrm{O}, \mathrm{Zn}, \mathrm{Ag}$ and $\mathrm{Fe}$ in the synthesized sample.

\subsection{Antibacterial Activities}

The antibacterial activity of $\mathrm{Ag}$ (2 at.\%)-doped and $\mathrm{Ag}$ $(2$ at. $\%)+\mathrm{Fe}(3$ and 6 at.\%)-doped $\mathrm{ZnO}$ nanopowders was investigated against two Gram-negative bacteria, viz., V. cholerae and V. parahaemolyticus, and one Grampositive bacteria Staphylococcus aureus. The variation in the measured zone of inhibition values is presented in the bar diagram (Fig. 9), and the incorporation of $\mathrm{Ag}$ into the $\mathrm{ZnO}$ lattice improves the antibacterial efficiency of the $\mathrm{ZnO}$ nanopowder [25]. The observed enhancement in the inhibition zones after $\mathrm{Fe}$ doping indicates the better antibacterial efficiency of the co-doped $(\mathrm{Ag}+\mathrm{Fe}) / \mathrm{ZnO}$ nanopowders as shown in (Fig. 10a-c). The improved antibacterial efficiency after $\mathrm{Fe}$ addition may be due to the increase in the carrier concentration caused by the substitution of $\mathrm{Fe}^{3+}$ ions into the $\mathrm{Zn}^{2+}$ sites. It is well known that substitution of each $\mathrm{Fe}^{3+}$ ion results in a release of one free electron. As reported by several researchers, this increased free electrons induce the generation of ROS (superoxide anion, hydroxyl radical, and hydrogen peroxide) in the system [26]. Moreover, the decrease in the crystallite size as well as the grain size caused by Fe doping may also be another reason for the enhancement in the antibacterial efficiency of the samples.

\section{Conclusions}

The investigation of antibacterial efficiency of $(\mathrm{Ag}+\mathrm{Fe})$ doped $\mathrm{ZnO}$ nanopowders showed that the sample with $(2+6)$ at. $\% \mathrm{Ag}+\mathrm{Fe}$ exhibits better antibacterial activity against V. Cholerae, V. Parahaemolyticus, and S. aureus bacterial organisms. The reduction in the grain size and the increase in reactive oxygen species caused by co-doping $(\mathrm{Ag}+\mathrm{Fe})$ play major role in enhancing the antibacterial efficiency of $\mathrm{ZnO}$ nanopowders.

Acknowledgments The authors gratefully acknowledge the Secretary and Correspondent, Principal, Dean of Sciences and Head of the Department of Physics, AVVM Sri Pushpam College (Autonomous), Poondi, Thanjavur 613 503, Tamil Nadu, India, for their encouragement and support. One of the authors P. Sathish gratefully acknowledges the financial assistance from the director of collegiate education, Govt. of Tamil Nadu, Chennai.

\section{References}

[1] K.B. Dermenci, B. Genc, B. Ebin, T.O. Hanci, S. Gürmen, J. Alloys Compd. 586, 267 (2014)

[2] R. Zamiri, B.K. Singh, D. Dutta, A. Reblo, J.M.F. Ferreira, Ceram. Int. 40, 4471 (2014)

[3] C.-W. Chang, H.-T. Wu, S.-H. Huang, C.-K. Chen, I.-W. Un, Acta Mater. 61, 6993 (2013)

[4] K. Ravichandran, P. Sathish, S. Snega, K. Karthika, P.V. Rajkumar, K. Subha, B. Sakthivel, Powder Technol. 274, 250 (2015)

[5] C. Huo, H. Yang, Appl. Clay Sci. 50, 362 (2010)

[6] K. Saravanakumar, B. Sakthivel, K. Ravichandran, Mater. Lett. 65, 2278 (2011)

[7] F.M. Ali, M.K. Abu-Assy, S. El-Gazzar, M. Iqbal, M. Hussain, Mater. Sci. Poland. 30, 248 (2012)

[8] Y.C. Lee, C.S. Yang, H.J. Huang, S.Y. Hu, J.W. Lee, C.F. Henge, C.C. Huanga, M.K. Tsai, H.C. Kuanga, J. Lumin. 130, 1756 (2010)

[9] N.L. Tarwal, P.R. Jadhav, S.A. Vanalakar, S.S. Kalagi, R.C. Pawar, J.S. Shaikh, S.S. Mali, D.S. Dalavi, P.S. Shinde, P.S. Patil, Powder Technol. 208, 185 (2011) 
[10] N. Jabena, K. Begum, J. Phys. Chem. Solids 74, 841 (2013)

[11] K. Ravichandran, R. Mohan, N. Jabena Begum, K. Swaminathan, C. Ravidhas, J. Phys. Chem. Solids 74, 1794 (2013)

[12] K. Ravichandran, K. Karthika, B. Sakthivel, N. Jabena Begum, S. Snega, K. Swaminathan, V. Senthamilselvi, J. Magn. Magn. Mater. 358-359, 52 (2014)

[13] M. MehediHassan, W. Khan, A. Azam, A.H. Naqvi, J. Lumin. 145, 160 (2014)

[14] K. Ravichandran, R. Rathi, M. Baneto, K. Karthika, P.V. Rajkumar, B. Sakthivel, R. Damodaran, Ceram. Int. 41, 3390 (2015)

[15] K. Saravanakumar, K. Ravichandran, J. Mater. Sci. Mater. Electron. 23, 1462 (2012)

[16] R. Saleh, S.P. Prakoso, A. Fishli, J. Magn. Magn. Mater. 324, 665 (2012)

[17] Z. Pan, X. Tian, S. Wu, X. Yu, Z. Li, J. Deng, C. Xiao, G. Hu, Appl. Surf. Sci. 265, 870 (2013)
[18] M. Lia, J. Xu, X. Chen, X. Zhang, Y. Wu, P. Li, X. Niu, C. Luo, L. Li, Superlattices Microstruct. 52, 824 (2012)

[19] Z.X. Yang, W. Zhong, C.T. Au, X. Du, H.A. Song, X.S. Qi, X.J. Ye, M.H. Xu, Y.W. Du, J. Phys. Chem. C 113, 21269 (2009)

[20] L.V. Trandafilovic, D.K. Bozanic, S. Dimitrijevic-Brankovic, A.S. Luyt, V. Djokovic, Carbohydr. Polym. 88, 263 (2012)

[21] K. Ravichandran, S. Snega, N. JabenaBegum, K. Swaminathan, B. Sakthivel, L. ReneChristena, G. Chandramohan, S. Ochiai, Superlattices Microstruct. 69, 17 (2014)

[22] S. Singhal, J. Kaur, T. Namgyal, R. Sharma, Phys. B Condens. Matter. 407, 1223 (2012)

[23] Y.Q. Wang, L. Su, L. Liu, Z.M. Tian, T.Q. Chang, Z. Wang, S.Y. Yin, S.L. Yuan, Phys. Status Solidi A 207, 2553 (2010)

[24] S. Yi, J. Cui, S. Li, L. Zhang, D. Wang, Y. Lin, Appl. Surf. Sci. 319, 230 (2014)

[25] J. Sawai, J. Microbiol. Method 54, 177 (2003)

[26] O. Yamamoto, Int. J. Inorg. Mater. 3, 643 (2001) 